\title{
Autonomia, construtivismo e razão pública: Rawls leitor de Kant
}

\author{
Rúrion Melo ${ }^{1}$ \\ rurionsm@hotmail.com \\ Universidade Federal de São Paulo, Guarulhos, São Paulo, Brasil
}

resumo Com a finalidade de refletir sobre a reatualização de autores clássicos da filosofia como forma de se enfrentar os desafios contemporâneos da democracia e do pensamento político, o artigo pretende apresentar a interpretação feita por John Rawls de aspectos da filosofia prática de Kant. Três conceitos são particularmente importantes nessa articulação entre a filosofia kantiana e o projeto rawlsiano de justificação normativa do liberalismo político: a concepção de pessoas morais autônomas, a fundamentação normativa ancorada em um procedimento de construção de tipo kantiano e a ideia de razão pública que orienta a deliberação racional dos cidadãos em uma democracia constitucional. Procuraremos problematizar se a pretensão de justificação normativa baseada no ponto de vista moral imparcial e representada pelo procedimento de construção pode ser mantida juntamente com a necessidade de também tratar a justificação dos princípios do liberalismo político como derivada de ideias intuitivas fundamentais consideradas latentes na cultura política pública. palavras-chave John Rawls; Kant; Autonomia; Razão Pública; Construtivismo Kantiano; Cultura Política Pública.

Desde a publicação de Uma teoria da justiça de John Rawls em 19712, a tradição kantiana pareceu dominar a pauta da filosofia política de cunho normativo. Colocou-se no centro da situação filosófica do presente a relação entre moral e política, procurou-se determinar o fundamento normativo para os problemas da justiça, defendeu-se a prioridade do justo diante de concepções particulares do bem, discutiu-se a urgência dos direitos humanos em sua relação com a soberania popular etc. Tanto 
na obra de Rawls como na teoria da ação comunicativa desenvolvida, por exemplo, por Jürgen Habermas, podemos identificar, na base de suas respectivas críticas sociais, um núcleo normativo comum que pode ser descrito como fundamentalmente kantiano. ${ }^{3}$ No que diz respeito a Rawls, filósofo do qual nos ocuparemos na presente exposição, essa filiação a Kant também é explícita e foi abordada não apenas por diversos comentadores $^{4}$ como gerou ainda uma reação por parte dos críticos ao liberalismo de fundamentação kantiana. ${ }^{5}$ De fato, os aspectos kantianos encontram-se em diferentes dimensões e momentos da obra de Rawls. Contudo, acreditamos que os três conceitos que permitem determinar uma unidade comum a tal teoria normativa dizem respeito ao conceito de autonomia, ao uso de um procedimento de construção para fundamentar o ponto de vista moral e à sua correspondente formulação da razão pública.

Pretendemos apresentar essa ideia e problematizá-la em três etapas. Primeiramente, gostaríamos de abordar de que modo podemos entender um dos conceitos rawlsianos centrais, a saber, o de posição original, como uma representação procedimental do imperativo categórico de Kant (I). Em seguida, gostaríamos de compreender melhor essa arquitetônica prática que Rawls entendeu inicialmente a partir de um construtivismo kantiano - depois definindo-o propriamente como "construtivismo político" - cuja afinidade com os conceitos do filósofo alemão parece bem mais complexa do que reconhecem tanto alguns intérpretes e críticos de Kant como respectivas leituras contemporâneas do kantismo (II). A posição original, e seu papel no interior de um construtivismo de tipo kantiano, estabelece de forma abrangente as determinações da autonomia como condições de aceitabilidade racional e é fundamental para o reconhecimento público dos princípios que produz. Por isso, concluirei chamando atenção, ainda que de forma sucinta, para a importância e também para certos limites da ideia de razão pública na justificação normativa de sua teoria (III).

\section{I}

Há uma interpretação comum de acordo com a qual a moral kantiana pode ser considerada, em grande medida, uma moral formal ou forma- 
lista. Contudo, isso não deve ser entendido aqui em sentido negativo. Kant fundamenta seu princípio da moralidade recorrendo a algumas distinções importantes, tais como natureza e razão, fenômeno e númeno, empírico e transcendental, felicidade e moralidade, máxima subjetiva e lei universal etc, distinções essas que são normativamente cheias de consequências. Essas distinções estipulam que a moral moderna não pode ser fundamentada em interesses particulares utilitaristas ou em uma ética da felicidade de tipo aristotélica, mas na razão prática pura. A razão é associada à ausência dos desejos e paixões, e o exercício da autonomia é entendido como um processo em que o agente racional precisa conformar tais desejos e paixões a uma lei moral a priori - lei esta, é preciso frisar, que o próprio sujeito dá a si mesmo segundo o princípio de autolegislação.

O que nos leva, por conseguinte, a entender sua moral também como "formal" na medida em que Kant sintetiza tais exigências da razão prática pura na formulação do imperativo categórico: "Age apenas segundo uma máxima tal que possas ao mesmo tempo querer que ela se torne lei universal"(KANT, 1995, p. 59). Kant não caracteriza a autonomia simplesmente como uma ação cuja máxima não é contraditória com sua universalização, mas assim o faz de um modo radicalmente novo, ou seja, de um modo procedimental. Em vez de orientar minha ação com base em máximas concebidas como prescrições substantivas do que devo ou não devo fazer, tenho de lançar mão de uma regra prática capaz de testar se determinadas máximas, que podem ser apenas expressão subjetiva de certos valores ou concepções do bem, podem também ser aceitas e consideradas válidas por qualquer outra pessoa. Não basta assim que eu decida por uma máxima simplesmente porque a considero melhor para meus próprios propósitos (segundo minha visão de mundo e concepção de bem que endosso), mas antes porque, em caso de conflito de valores, devemos fazer aquilo que é igualmente bom para todos. Por um lado, o imperativo categórico corresponde, assim, ao caráter impessoal de mandamentos morais válidos; por outro lado, sua justificação normativa pode ser exposta no próprio procedimento que a autodeterminação assume na forma legislativa do teste procedimental a que submetemos máximas e normas (Cf. KANT, 2002, \$\$1-8).

Rawls mistura à interpretação do imperativo categórico kantiano elementos específicos do próprio vocabulário de sua filosofia política. No 
caso de Kant, trata-se de perceber como é possível fundamentar a idéia da autonomia de modo que "não exista qualquer ordem moral prioritária ou independente dessas concepções que determinam a forma do procedimento que especifica o conteúdo dos deveres da justiça e da virtude" (RAWLS, 2000, p. 236-237). Com a estratégia kantiana de fundamentação do princípio moral passamos a não compreender a justificação da normatividade basicamente a partir de elementos empíricos (natureza, objetos sensíveis, sentimentos e inclinações etc.), mas segundo uma "lei moral que, entendida como razão prática pura, determina (constrói) seu objeto a partir de si mesma”. (RAWLS, 2000a, p. 235). Tal estratégia nos remete novamente ao importante papel do imperativo categórico para a justificação da normatividade.

Isso fica patente em seus Cursos de filosofia moral, onde o imperativo categórico é chamado de "procedimento IC" e pode ser analisado em quatro passos (RAWLS, 2000a, p. 167 e ss.). O primeiro passo diz respeito à relação do agente com a máxima da ação. Embora a máxima seja subjetiva e venha a ser escolhida com base na situação, nas alternativas, nos desejos e nas concepções de bem, Kant teria ressaltado nesse momento simplesmente a capacidade racional da pessoa em escolher, de forma consequente, normas de ação. Basta compreender inicialmente no procedimento que a máxima é subjetivamente válida uma vez que foi determinada racionalmente pelo próprio agente. No segundo passo, há a generalização da máxima, ou seja, o preceito da universalização. Neste caso, a validade da máxima não depende somente da capacidade racional subjetiva da pessoa, mas do fato de poder ser aceita por todo ser racional. No terceiro passo, procurando tornar o imperativo categórico mais "intuitivo", representamos a lei universal como se fosse uma lei da natureza. Por fim, no quarto passo, ajustamos o "como se" aos dois primeiros passos e criamos assim um mundo social equilibrado. Ao realizar esse ajuste, imputamos ao agente racional do primeiro passo uma intenção legisladora, de modo que seria somente o agente racional o responsável por legislar, a partir de sua própria autonomia da vontade, sobre as regras que organizam e regulam esse mundo.

A exposição desse procedimento pressupõe um elemento essencial para a compreensão da autonomia, a saber, a caracterização da pessoa moral como "racional" e "razoável". Kant havia percebido que sujeitos 
racionais partem de concepções existentes sobre o bem viver, a realização da felicidade etc, segundo costumes correntes. Kant certamente não oferece um modo alternativo a ser seguido, ou seja, não prescreve regras práticas substantivas para a condução moral da vida. Ele limita-se antes ao teste de máximas de acordo com a autonomia da vontade. Isso significa, primeiramente, pressupor um agente racional (no vocabulário rawlsiano, uma pessoa moral racional) capaz de escolher reflexivamente sua própria máxima, o que implicaria revisar racionalmente seus próprios interesses, visão de mundo e concepções de bem. Entende-se aqui que o "procedimento IC", embora seja formal (no sentido da adequação da validade da norma à forma da autolegislação), não é vazio. Rawls insiste que nossa consciência moral cotidiana (de onde surgem a "boa vontade" e o "fato da razão”) está pressuposta em nossa constituição como pessoas morais. O procedimento de construção nada mais faria do que representar as exigências tanto empíricas como puras na relação das máximas com a autonomia da vontade.

Com isso, preenchem-se duas condições essenciais que o imperativo categórico deveria satisfazer de um ponto de vista normativo. Primeiro, embora procedimental, a construção do imperativo categórico não pode ser meramente formal, pois precisa "especificar as exigências sobre a deliberação moral de modo que muitas máximas possam ou não se tornar lei universal” (RAWLS, 2000a, p. 254). Se essa primeira condição diz respeito ao conteúdo testado pelo procedimento, a segunda, ainda de acordo com Rawls, diz respeito à liberdade, uma vez que "o imperativo categórico precisa representar a lei moral como um princípio da autonomia” (RAWLS, 2000a, p. 254). Apenas se a lei moral se fundar na autonomia é possível a autocompreensão da pessoa moral como livre, uma vez que nossa ação racional independe de qualquer ordem empírica e natural ao agirmos a partir dos princípios de uma razão prática pura.

Nesse ponto já começamos a abandonar o ponto de vista meramente racional, ligado à escolha das máximas, para a derivação normativa do procedimento na caracterização do razoável. "O procedimento do imperativo categórico de Kant", comenta Rawls em outro de seus livros, "submete as máximas racionais e sinceras de um agente (formulada à luz da razão empírica do agente) às restrições razoáveis contidas naquele procedimento, submetendo assim a conduta do agente às exigências da 


\section{2}

razão prática pura" (RAWLS, 2001a, p. 81). Como vimos nos passos acima descritos do "procedimento IC", a própria escolha racional da máxima nos leva a testar sua validade perante todo outro ser racional. Outra pessoa pode certamente aceitar minha máxima (ou a máxima que regula determinada coletividade) para a condução prática de sua vida por diversos motivos empíricos. Porém, a justificação normativa oferecida por Kant requer que a universalidade da máxima dependa intrinsecamente da forma legislativa exposta pelo "procedimento IC". Segundo comentários de Rüdiger Bittner, se no primeiro passo do procedimento se descreve aquilo que vale apenas em razão de minha decisão para minha vida, no segundo "a regra universal que quero em uma escolha autônoma da máxima precisa, portanto, como seu princípio, ser: aquilo que é de todo sujeito" (BITTNER, 2003, p. 24). E todo sujeito possui igualmente a capacidade moral de querer racionalmente seguir uma máxima que ele mesmo se deu. A construção do procedimento é razoável na medida em que permite o igual exercício de uma legislação autônoma e submete a justificação normativa a uma lei moral da razão prática pura. Ao pressupor pessoas morais iguais, a escolha racional precisa se submeter à razoabilidade de um procedimento que determina a validade de uma máxima como lei moral somente quando tal máxima puder ser aceita por toda outra pessoa moral igualmente racional.

Delineia-se nessa interpretação bastante peculiar da letra de Kant a ideia central de autonomia a ser defendida por Rawls segundo a qual agimos de forma autônoma quando obedecemos estritamente às leis que todos os envolvidos poderiam aceitar com boas razões, com base em um uso público da razão. O procedimento precisa representar uma autoatividade legisladora responsável pela fundamentação de princípios e normas que organizarão a sociedade política. Por isso ser tão importante essa prioridade kantiana do aspecto razoável da razão prática e do procedimento frente ao meramente racional. Não há uma separação entre o racional e o razoável em Kant. Mais do que isso, há uma subordinação do racional ao razoável. "A razoabilidade”, comenta Denilson Werle, "juntamente com a idéia de razão pública e o princípio da publicidade, expressa uma forma intersubjetiva de virtude política, fundamentada no reconhecimento político do outro como livre e igual. Nesse sentido, o conceito de razoabilidade é essencial para a moralidade política liberal, e 
especialmente importante para pensar as idéias principais de razão pública e legitimidade democrática, isto é, o princípio liberal de legitimidade fundado no critério de reciprocidade" (WERLE, 2008, p. 47).

Não vamos nos deter na interpretação do imperativo categórico tal como foi exposta em seus Cursos de filosofia moral. Esse mesmo propósito de especificar procedimentalmente as condições ideais da aceitabilidade racional receberá outra forma, esta ainda mais importante para nossa discussão, no artifício representativo da posição original, em que Rawls desenvolve sistematicamente sua própria teoria. Saímos do quadro de uma doutrina moral abrangente (embora formal), tal como aquela de Kant, e especificamos nosso objeto no campo do político, uma vez que precisamos derivar princípios de justiça válidos, passíveis de serem publicamente reconhecidos, que serão constitutivos das instituições básicas da sociedade. Esse consiste o propósito de uma teoria da justiça como equidade pensada a partir da noção kantiana de autonomia

Como entender, portanto, o artificio da posição original como uma representação procedimental do imperativo categórico kantiano? Em busca da fundamentação dos princípios de justiça de uma sociedade bem ordenada, Rawls segue um procedimento que pode ser interpretado como a explicação do ponto de vista da avaliação imparcial de questões de justiça política: a noção de procedimento toma forma na construção teórica de Rawls com a finalidade de esclarecer o ponto de vista a partir do qual poderíamos responder à questão de saber como é possível fundamentar princípios que estabeleçam uma cooperação justa e imparcial entre cidadãos livres e iguais. As instituições básicas de uma sociedade precisariam ser fundamentadas do "ponto de vista moral", isto é, do ponto de vista da justiça, para poderem ser interpretadas como resultado de um acordo mutuamente aceitável. A posição original surge como um artifício conceitual que dá forma à ideia de que seria possível encontrar procedimentos razoáveis de decisão para uma justa avaliação de interesses em conflito.

Rawls parte de teorias familiares do contrato social (que não se limitam a Kant, mas também estão presentes em Locke ou Rousseau) para chegar a um modo de representação compatível com a idéia de que princípios de justiça são objetos de um acordo racional (RAWLS, 1999, $\$ \$ 3-4)^{6}$. "A justiça como equidade", comenta Rawls em seu livro O libe- 


\section{4}

ralismo político, "retoma a doutrina do contrato social (...): os termos equitativos da cooperação social são concebidos como um acordo entre as pessoas envolvidas, isto é, entre os cidadãos livres e iguais, nascidos numa sociedade em que passam sua vida. Mas esse acordo, como qualquer acordo válido, deve ser estabelecido em condições apropriadas. Em particular, essas condições devem situar equitativamente as pessoas livres e iguais, não devendo permitir a algumas pessoas maiores vantagens de barganha do que outras. Além disso, coisas como a ameaça do uso da força, a coerção, o engodo e a fraude devem ser excluídas" (RAWLS, 2000b, p. 66). O artificio estabelece hipoteticamente assim uma situação inicial de escolha, um "status quo inicial apropriado", capaz de garantir que todos os concernidos ocupem desde o início posições equitativas, e que por sua vez o resultado do acordo fundamental alcançado, isto é, os dois princípios de justiça escolhidos nesta posição, sejam justos.

Há duas maneiras de compreender a idéia de imparcialidade a partir da posição original. A imparcialidade pode ser compreendida, primeiramente, por meio de seu estatuto "hipotético" e "aistórico", meramente artificial. Considerada um artifício de representação, a posição original ilustraria aquele ponto de vista não distorcido pelas características e circunstâncias da estrutura básica de alguma sociedade particular e concreta. Nesse sentido, o procedimento da posição original pode ser entendido como um tipo de "experimento mental" em que se representam as condições imparciais da aceitabilidade racional. Porém, além disso, há um elemento representativo no interior do procedimento que deixa ver que a ideia de imparcialidade seria, antes de tudo, uma condição necessária inscrita no pressuposto normativo de que princípios de justiça seriam objetos de um acordo racional: para que os princípios de justiça fossem os mais adequados para uma cooperação social justa, os termos equitativos da cooperação deveriam ser concebidos de acordo com a autonomia de cada um dos cidadãos.

É importante ressaltar que, para assegurar a validade dos princípios de justiça e, por sua vez, a imparcialidade almejada pelo procedimento, as partes representadas na posição original e que deliberam racionalmente a partir de uma situação inicial equitativa estão privadas de informações sobre características e situações particulares. Eles devem escolher sem considerar seus próprios interesses e necessidades, ou interesses e necessi- 
dades dos outros, concepções de bem ou visões de mundo. Para que o procedimento possa figurar essa exigência normativa da imparcialidade, Rawls lança mão do artificio do véu de ignorância. As partes na posição original escolhem por trás de um véu de ignorância, artificio que permite abstrair as contingências do mundo social e eliminar as vantagens de barganha que surgem nas instituições políticas realmente existentes. $\mathrm{O}$ acordo equitativo só pode ser produzido, entende Rawls, se as partes estiverem simetricamente situadas e escolherem sob condições igualmente restritivas. As restrições quanto à realidade social, histórica ou psicológica se justificaria pelo fato de o artifício procedimental se limitar apenas à representação da liberdade (ao atribuir às partes a capacidade de escolha racional) e da igualdade (ao limitar as informações de forma figurada com o véu de ignorância). Nas palavras do próprio Rawls, "a posição original é apenas um artifício de representação: descreve as partes, cada qual responsável pelos interesses essenciais de um cidadão livre e igual, numa situação equitativa, alcançando um acordo sujeito a condições que limitam apropriadamente o que podem propor como boas razões" (RAWLS, 2000b, p. 68).

A posição original é, assim, o artifício empregado por Rawls para responder à questão de como poderíamos determinar os termos equitativos de cooperação uma vez que oferece "um ponto de vista a partir do qual um acordo equitativo entre pessoas consideradas livres e iguais possa ser estabelecido" (RAWLS, 2000b, p. 66). Nesse sentido, àquele mesmo problema solucionado por Kant com o imperativo categórico o de saber como é possível justificar racionalmente em casos de conflito normas de ação que sejam igualmente boas para todas as pessoas - Rawls oferece o artifício da posição original ao aplicar o procedimento às condições de uma estrutura básica da sociedade. Segundo o próprio autor, "a posição original pode ser vista como uma interpretação procedimental do conceito de autonomia e de imperativo categórico de Kant no quadro de uma teoria empírica" (RAWLS, 1999, p. 226). Se, como vimos acima, Kant submetia o agente racional às restrições razoáveis de uma razão prática pura, "de maneira similar as condições razoáveis impostas às partes na posição original os constringem a alcançar um acordo racional sobre princípios de justiça em que cada qual procura defender o bem daqueles que representa. Em cada caso, o razoável tem priori- 
dade sobre o racional e o subordina inteiramente. Essa prioridade expressa a prioridade do justo; e é por causa disso que a justiça como equidade se assemelha à visão de Kant" (RAWLS, 2001, p. 81-82).

Essas limitações impostas sobre a história, a posição social, as crenças e concepções abrangentes sobre a vida boa se encontram no cerne da tese liberal que afirma a prioridade do justo sobre o bem. Pois fundamentamos a validade normativa não com base em dimensões axiológicas ou utilitárias, mas simplesmente sob as condições mínimas de aceitabilidade racional. Logo, o justo possui uma prioridade normativa frente ao bem na medida em que os princípios de justiça não precisam depender, para sua justificação, de qualquer concepção particular de vida boa. Derivam dessa necessária abstração em que se compõe a estrutura do procedimento as críticas comunitaristas como aquelas de Michael Sandel, para quem a teoria de Rawls se assentaria sobre um "sujeito desencarnado", ao enfatizar a escolha racional em detrimento da reflexão e ao configurar a autonomia a partir da privação das informações, deixando de notar que o mais importante seriam justamente aqueles valores que permaneceriam escondidos por debaixo do véu de ignorância (Cf. SANDEL, 2005). Não nos parece inteiramente correta essa leitura dos textos de Rawls que escamoteia a importância dos elementos propriamente reflexivos presentes em sua teoria. Acreditamos que a tentativa de articulação entre procedimento e reflexão caracteriza um dos planos centrais do construtivismo kantiano.

\section{II}

O "procedimento IC" é o núcleo do construtivismo kantiano. Porém, segundo nos mostra Rawls, o próprio procedimento não pode ser resultado da construção. O construtivismo kantiano especifica que os conteúdos de nossa doutrina moral (normas e leis morais) não são normativamente válidos sem que resultem do princípio da autonomia. E se a autonomia for entendida como a atividade legislativa da própria razão prática, o procedimento - ou seja, os passos da forma legislativa - não é outra coisa senão a exposição dessa atividade. É nesse sentido que devemos entender a afirmação de Rawls segundo a qual o próprio "procedi- 
mento IC" não pode ser construído, mas simplesmente apresentado ou exposto (laid out). (RAWLS, 2000a, p. 239). O pressuposto fundamental para a construção é a própria concepção de pessoa antes aludida. Kant havia percebido que todo ser humano racional está constituído por elementos da razão prática, sejam eles puros ou empíricos. O procedimento de construção apenas reflete a concepção de pessoa moral racional e razoável. Uma vez que o procedimento não é construído, mas exposto, o que se apresenta é reflexo dessa concepção geralmente aceita de pessoa moral: “A concepção de pessoas livres e iguais, racionais e razoáveis, é a base da construção" (RAWLS, 2000a, p. 241). Com o construtivismo kantiano podemos especificar uma concepção particular de pessoa como um elemento básico do procedimento de construção.

O construtivismo permitirá ainda compreender os vínculos entre elementos empíricos e puros nas exigências da razão prática e rebater as críticas contra um suposto formalismo vazio ou antirrealismo na estratégia kantiana. Pois também encontramos em Kant uma exigência por objetividade que o construtivismo configura em diferentes momentos. $\mathrm{O}$ imperativo categórico condensa uma parte central desses momentos uma vez que o princípio moral construído se conforma aos critérios do racional e do razoável como reflexo de pessoas morais livres e iguais. Um juízo moral adequado acaba combinando tais critérios e exigências de nossa razão prática no "procedimento IC". Desse modo, os princípios morais e políticos podem ser normativamente justificados porque são passíveis de reconhecimento por toda pessoa razoável e racional. Essa universalidade da lei moral é objetiva porque pressupõe a formação de um juízo adequado por parte de pessoas que deliberam racionalmente segundo procedimentos razoáveis de autodeterminação.

Essa universalidade pretende objetividade ainda no momento da justificação publica. Para o construtivismo kantiano, uma concepção de objetividade depende de como se produzem acordos bem informados. $\mathrm{O}$ acordo é possível no quadro do construtivismo porque, em primeiro lugar, pressupõe-se uma razão prática comum. "Pessoas razoáveis e racionais", diz Rawls, "têm de reconhecer mais ou menos as mesmas razões e lhes atribuir o mesmo peso" (RAWLS, 2000a, p. 244). Em outros termos, não importaria, para a estratégia de fundamentação kantiana, saber exatamente quem aplica o "imperativo IC", mas somente saber se o 


\section{8}

procedimento foi aplicado de maneira adequada e consciente diante de crenças e informações razoavelmente semelhantes. O que importa, na verdade, é perceber que todos nós somos moralmente capazes de, na maioria das vezes, chegar a acordos com base em juízos válidos, isto é, segundo "critérios da razão prática publicamente reconhecidos" (RAWLS, 2000a, p. 244). Convicções morais podem ser objetivas então se pessoas racionais e razoáveis puderem utilizar sua razão prática e, neste caso, suas capacidades morais para aferir a validade das máximas que pretendem reconhecimento. Pois existem razões suficientes para convencer todas as pessoas razoáveis de que certa convicção moral é ou não válida, de que tais razões podem ser justificadas publicamente diante de uma comunidade constituída por tais pessoas.

Talvez uma analogia com o que podemos entender por construção na teoria de Kant seja elucidativa para os problemas em questão. Porém, acreditamos que Onora O’Neill chegou a uma formulação mais adequada e mais sistemática sobre o construtivismo kantiano na letra do próprio Kant do que a interpretação de Rawls permite ver (Cf. O’NEILL, 1989). A tese central de O'Neill traz muitas dificuldades para a crítica hegeliana ao kantismo, sobretudo à conhecida afirmação de Hegel de que a filosofia prática de Kant está fundada no "formalismo vazio" do imperativo categórico. Em linhas gerais, a autora mostra que a fundamentação transcendental do criticismo kantiano - ou seja, o sujeito transcendental ou a razão prática pura - embora possua uma pretensão aistórica de validade, depende de condições "públicas" para se autolegitimar, sem que isso implique cair no relativismo. Por um lado, a crítica da razão só se tornou possível na "época da crítica”, ou seja, com o desenvolvimento moderno da física, do direito e do liberalismo político. Por outro lado, o esclarecimento permitiu a Kant construir as condições transcendentais da autonomia e da crítica que essa mesma época simultaneamente pressupôs e promoveu. É por isso que a vontade livre, concebida como atividade legisladora primária de um ser numênico, só poderia se constituir no espaço público em que podemos comunicar livremente nossos pensamentos (Cf. KANT, 1977, p. 53-61). Por conseguinte, a concepção do próprio Kant para a justificação da normatividade seria mais radicalmente "construtiva" do que a de Rawls (Cf. O’NEILL, 2003, p. 354), trazendo consequências políticas importantes, como veremos ao final do presente artigo. 
Mas retomando o argumento, é possível notar analogamente que os agentes da construção são considerados segundo pessoas morais que se compreendem no mundo social - no caso da teoria de Rawls, como cidadãos livres e iguais de democracias constitucionais. É por essa razão que os princípios são escolhidos a partir daqueles procedimentos que os agentes da construção poderiam razoavelmente seguir. E ao se voltar para a cultura pública de uma sociedade democrática pressuposta, "o construtivismo kantiano”, diz Rawls, “espera invocar uma concepção de pessoa afirmada implicitamente nessa cultura, ou seja, aquela concepção que poderia se mostrar a mais aceitável para os cidadãos, uma vez que lhes tenha sido adequadamente apresentada e esclarecida" (RAWLS, 2001b, p. 306). A razão prática se manifesta na capacidade moral de cidadãos de democracias constitucionais, e estas permitem construir objetivamente as capacidades dos cidadãos no exercício da faculdade da razão prática e sua representação. Podemos comunicar nossos juízos práticos e especificá-los segundo uma concepção política de justiça (razoável e reconhecível) porque o exercício da reflexão prática é compartilhado por pessoas racionais e razoáveis. Um procedimento construtivista pode especificar quais fatos relativos a ações, instituições e ao mundo social (como a escravidão ou a tolerância religiosa) são relevantes para a deliberação política, bem como gerar princípios para identificar quais fatos podem ser considerados objetivamente como razões.

Além de reinterpretar o procedimento do imperativo categórico como um artifício representativo das condições equitativas de aceitabilidade racional, Rawls também oferece uma justificação reflexiva para a autonomia em sua teoria da justiça como equidade. Esse seria o outro componente complexo do construtivismo kantiano, limitado não somente à construção do conteúdo dos princípios morais e políticos, mas proporcionando uma forma adequada com que a teoria pode requerer objetividade. Pois a ação autônoma não é medida apenas por sua conformidade com uma lei moral a priori - uma vez que, no caso de Kant, pode-se entender que o imperativo categórico deriva da análise da estrutura da razão prática pura - mas resulta daqueles princípios que refletem nossa autocompreensão como cidadãos livres e iguais que compartilham de uma cultura pública democrática. Por conseguinte, os princípios escolhidos na posição original não poderiam ignorar aspec- 


\section{0}

tos históricos e sociais em que estamos inseridos. Kenneth Baynes chega a afirmar que "Rawls reconhece a natureza social das pessoas mais profundamente do que Kant: $O$ fato de que quem somos seja formado em grande medida pelas instituições sociais em que estamos enraizados consiste numa consideração fundamental ao se tratar a estrutura básica da sociedade como o primeiro objeto da justiça”" (BAYNES, 1992, p. 4). Em outras palavras, o aspecto estrutural da posição original como um todo, sob o qual as partes se situam e limitam suas informações (a situação inicial e o véu de ignorância), corresponderá ao ponto de vista dos cidadãos considerados pessoas morais livres e iguais; e estes, por sua vez, podem lançar mão da posição original para elucidar a validade dos princípios escolhidos a partir de uma situação inicial equitativa. Porém, a relação dos cidadãos com a posição original tem de ser entendida não apenas pelo aspecto estrutural, mas, sobretudo, pelo vínculo que pretende manter com o mundo social. E essa objetividade exigida é certamente necessária para que os cidadãos possam agir de forma plenamente autônoma. ${ }^{7}$

Esse vínculo é representado procedimentalmente pela posição original, mas também pode ser avaliado por nossos próprios juízos sobre a justiça. Rawls se refere a esse processo de ajuste entre juízos e procedimento como um equilíbrio reflexivo. A descrição da sociedade bem-ordenada e a caracterização da posição original, bem como os princípios de justiça, precisam corresponder a nossos "juízos ponderados”, ou seja, princípios que podemos escolher depois de devida reflexão. Acomodamos em um único processo de ajustamento os princípios que possibilitam configurar uma situação inicial equitativa de escolha com nossos juízos ponderados sobre a justiça. Nas palavras de Rawls, "trata-se de um equilíbrio porque, em última instância, nossos princípios e juízos coincidem; e é reflexivo uma vez que sabemos a quais princípios nossos juízos se conformam e as premissas de sua derivação" (RAWLS, 1999, p. 18). Alargamos assim a abrangência do construtivismo para além daquela representação da aceitabilidade racional em termos procedimentais.

Ora, o cerne do construtivismo sugerido por Rawls consiste em mostrar como esse movimento de ajustamento pode ser descrito e configurado. "O construtivismo político", comenta Rawls, "é uma visão relativa à estrutura e conteúdo de uma concepção política. Afirma ele 
que, depois de obtido o equilíbrio reflexivo, se isso vier a acontecer, os princípios de justiça política (o conteúdo) podem ser representados como o resultado de um certo procedimento de construção (a estrutura). Nesse procedimento, modelado de acordo com a posição original, os agentes racionais, enquanto representantes dos cidadãos sujeitos a condições razoáveis, selecionam os princípios públicos de justiça que devem regular a estrutura básica da sociedade. Esse procedimento, assim conjecturamos, sintetiza todos os requisitos relevantes da razão prática e mostra como os princípios de justiça resultam dos princípios da razão prática conjugados às concepções de sociedade e pessoa, também elas idéias da razão prática”. (RAWLS, 2000b, p. 134). Vemos aqui quase uma paráfrase de suas análises do construtivismo na obra de Kant. $\mathrm{O}$ artifício da posição original - exatamente como também Kant o teria feito no imperativo categórico - é configurado se pressupomos pessoas morais livres e iguais que possuem tanto uma capacidade de ter uma concepção de bem (e, neste caso, escolherem sua própria máxima de ação) quanto um senso de justiça (ou seja, adotarem o ponto de vista do outro, o qual, novamente em analogia com termos kantianos, corresponderia à conformação de sua máxima subjetiva de ação a uma lei universal).Vimos que a posição original pressupõe e representa procedimentalmente essas exigências normativas para caracterizar o conceito de autonomia. Porém, no construtivismo propriamente político é necessário atender ao fato de que os próprios cidadãos se compreendem como pessoas livres e iguais numa cultura política de um regime democrático constitucional. O objetivo da justiça como equidade é resolver como os valores da liberdade e da igualdade podem ser realizados da forma mais apropriada possível, e para tanto Rawls parte da ideia da sociedade como um sistema equitativo de cooperação, no qual esses termos são estabelecidos por um acordo entre os cidadãos concebidos como pessoas morais.

A objetividade que o construtivismo pode proporcionar ao liberalismo político rawlsiano implica, na verdade, não apenas uma articulação entre justiça política (e os conteúdos afirmados por ela) e a representação procedimental que faz parte da construção. Um importante problema consiste em mostrar que as partes na posição original representam cidadãos de democracias constitucionais altamente divididos pelo fato do pluralismo, mas que ainda assim podem ser pressupostos em concepções 


\section{2}

complexas de pessoas e de sociedade. Rawls sublinha esse ponto ao admitir que "a enorme importância de uma concepção política construtivista está em sua relação com o fato do pluralismo razoável e com a necessidade de uma sociedade democrática assegurar a possibilidade de um consenso sobreposto em relação a seus valores políticos fundamentais”(RAWLS, 2000b, p. 135). Assim como em Kant teríamos de pressupor critérios da razão prática que nos permitissem construir as condições mais adequadas para um acordo entre pessoas morais, o construtivismo político de Rawls desenvolve os princípios de justiça a partir das ideias públicas e compartilhadas da sociedade como um sistema cooperativo equitativo e de cidadãos livres e iguais, utilizando para tanto princípios de uma razão prática comum.

Trata-se de uma tentativa de mostrar objetivamente que os princípios de justiça podem ser entendidos como resultado de um processo de construção. Parte-se do ponto de vista que nós mesmos temos sobre a sociedade, a história, a economia e a psicologia em direção aos ideais de uma sociedade bem-ordenada; esses ideais são articulados com a posição original, como uma situação inicial equitativa de escolha; e das partes na posição original chega-se aos princípios de justiça. O procedimento construtivo expressa assim aqueles critérios relevantes de razoabilidade e racionalidade que se aplicam aos princípios e normas da justiça política. Considerados conjuntamente - razão prática, procedimento de construção, concepção de pessoa e de sociedade, e também a ideia do razoável aplicada a concepções e princípios, juízos e fundamentos, pessoas e instituições - os elementos objetivos do liberalismo político são esclarecidos no construtivismo e associados ao conteúdo de uma concepção política razoável. Rawls pressupõe a disposição razoável das pessoas para agir de acordo com termos equitativos de cooperação social e seu reconhecimento e disposição para aceitar as constrições razoáveis a que se submetem no procedimento. Mas, além disso, o construtivismo permite apresentar esse procedimento como a expressão formalizada de um "desejo comum" em torno do acordo político, como noções pressupostas e compartilhadas que sustentam os princípios de uma concepção pública de justiça. Quando se apresenta na cultura pública de uma sociedade democrática, a concepção de justiça precisa ser articulada e se manifestar como noções e princípios compartilhados latentes na sociedade. Conse- 
quentemente, a tarefa do construtivismo político é descobrir e formular as bases do acordo político que pressupomos na cultura política democrática, bem como originar e representar tais convicções segundo artificios procedimentais como aquele da posição original.

Com o construtivismo político é possível entender, portanto, como a determinação de tais termos equitativos, que resulta nos princípios de justiça, é derivada do interior da arquitetônica prática rawlsiana e está pressionada por critérios normativos exigentes de aceitabilidade racional, tornando difícil aceitar a denominação de Rawls por certos críticos como aquele que herdou de Kant um "formalismo vazio" ou como um "contextualista", cuja teoria refletiria meramente os valores publicamente partilhados da sociedade americana (Cf. RORTY, 1988, p. 257-288). É verdade que essa arquitetônica não está limitada à representação procedimental, pois a própria teoria precisa encontrar o reconhecimento público dos princípios que resultaram do procedimento. Contudo, esses dois aspectos parecem corresponder ao propósito da justificação da teoria da justiça como equidade do ponto de vista da autonomia e da razão pública: implicam simultaneamente - e não sem certa tensão - uma mediação reflexiva entre a forte pretensão de aceitabilidade racional dos princípios de justiça e a aceitação pública realizada em contextos de sociedades democráticas (Cf.WERLE, 2008, p. 36; e MELO, 2008, p. 116 e ss).

\section{III}

Além da posição original, também a idéia de razão pública especificará o ideal de aceitação pública das normas sociais e instituições tal como está constituído a partir do conceito de autonomia. $\mathrm{O}$ equilíbrio reflexivo com nossos juízos ponderados, o ponto de vista social construído de modo a permitir aceitação de todas as pessoas e a razão pública de cidadãos em uma sociedade democrática formam ainda o esquema de justificação da normatividade no construtivismo de tipo kantiano: exige-se que a sociedade seja regulada por princípios de justiça que sejam publicamente reconhecidos; ou melhor, a própria justificação destes princípios deve ser realizada com referência à noção de uma "razão pública livre". Pois uma sociedade bem-ordenada deveria satis- 


\section{4}

fazer os três níveis do que Rawls chama de "condição plena de publicidade" (RAWLS, 2001b, p. 325), cujo objetivo consiste em fazer com que os princípios e sua justificação possam ser aceitos por cada membro da sociedade.

No primeiro nível de publicidade, a sociedade deve ser regulada pelos princípios públicos de justiça escolhidos na posição original: por serem justos, esses princípios podem ser aceitos e reconhecidos por todos, e este reconhecimento é por definição "público". O segundo nível de publicidade diz respeito às "crenças gerais" junto com as quais os princípios de justiça podem ser aceitos. Ou seja, os métodos publicamente compartilhados de justificação e de argumentação estão enraizados numa cultura política pública própria de sociedades democráticas sob condições modernas. Essas crenças gerais refletem as visões públicas correntes numa sociedade bem-ordenada e permitem entender por que exatamente aqueles princípios de justiça foram escolhidos na posição original. Essa objetividade exigida pelos princípios oferecidos na teoria rawlsiana também se encontra no terceiro nível de publicidade, no qual Rawls diz que, caso nós - eu e você - tivéssemos que fazer uma justificação completa da concepção pública de justiça, esta justificação estaria presente na cultura pública, refletida no direito e nas instituições políticas, assim como nas interpretações dessas instituições tais como as encontramos nas tradições históricas e filosóficas.

"Contudo", lembra Kenneth Baynes, "não é qualquer argumento ou consideração que pode ser apropriadamente introduzido na discussão pública” (BAYNES, 1992, p. 74). Isso porque, sob as condições do fato do pluralismo, não seria possível alcançar um acordo sobre princípios se se apela ao que Rawls chamou de "doutrinas morais abrangentes" (sejam visões de mundo religiosas, teorias morais substantivas ou algum tipo específico de argumentação filosófica). As bases comuns do acordo político, ainda que refletidas nas idéias intuitivas fundamentais latentes na cultura política pública de uma sociedade democrática, estão limitadas às razões e princípios publicamente reconhecidos. "Os cidadãos", diz Rawls, "percebem que não podem chegar a um acordo ou se aproximar de um entendimento mútuo com base nas suas doutrinas abrangentes irreconciliáveis. Nesse sentido, precisam considerar que tipos de razões podem razoavelmente oferecer uns aos outros quando estão em jogo 
questões políticas fundamentais. Eu proponho que, na razão pública, doutrinas abrangentes referentes à verdade e ao justo sejam substituídas por uma idéia do politicamente razoável endereçado aos cidadãos enquanto cidadãos" (RAWLS, 2007, p. 145-146). Assim, o recurso à razão pública seria o modo legítimo por meio do qual uma sociedade política especificaria no nível mais profundo os valores morais e políticos básicos que determinam a relação de um governo democrático constitucional com seus cidadãos e suas relações uns com os outros.

Porém, a razão pública impõe limites, não podendo ser aplicada a todas as questões políticas: "A idéia de razão pública tem uma estrutura definida, e se um ou mais de seus aspectos são ignorados, pode parecer implausível, tal como quando aplicada à cultura de fundo. Esta idéia tem cinco diferentes aspectos: (1) as questões políticas fundamentais às quais ela se aplica; (2) as pessoas para as quais ela se aplica (representantes do governo e candidatos a cargos públicos); (3) seus conteúdos, na medida em que são dados por uma família de concepções políticas razoáveis de justiça; (4) a aplicação dessas concepções nas discussões das normas coercitivas a serem ordenadas na forma do direito legítimo para um povo democrático; e (5) para que os cidadãos possam verificar que os princípios derivados de suas concepções de justiça satisfazem o critério de reciprocidade" (RAWLS, 2007, p. 146-147). Em síntese, a razão pode ser pública de ao menos três maneiras: como a razão de cidadãos livres e iguais, ela é a razão do público. Além disso, sua própria matéria é o bem público, uma vez que concerne às questões da justiça política fundamental, a saber, aos elementos constitucionais essenciais e às questões da justiça básica. Por isso a afirmação forte, e também muito criticada, de Rawls de que "a razão pública é a razão de seu supremo tribunal”. (RAWLS, 2000b, p. 281). Por fim, a natureza e o conteúdo da razão são públicos, sendo expressos na argumentação pública por uma família de concepções de justiça política pensadas para satisfazer o critério de reciprocidade.

Ora, essa solução ralwsiana da razão pública para o problema da justificação - assim como toda arquitetônica pressuposta em seu construtivismo - acaba esbarrando num "paradoxo da justificação democrática" (Cf. BAYNES, 1992, p. 74-76). Pois o construtivismo de Rawls oscilaria necessariamente entre a exigência liberal de imparcialidade especificada pela posição original e o ancoramento reflexivo das ideias intuitivas funda- 


\section{6}

mentais presentes na cultura pública de regimes democráticos. O paradoxo surge do modo como as idéias políticas da razão pública expressariam um modus vivendi incapaz de escapar das críticas ao relativismo. Neste ponto, talvez a solução de Habermas ao interpretar o uso público da razão a partir de uma teoria do discurso pudesse ser um dos únicos caminhos para evitar o paradoxo sem abrir mão daquelas pretensões normativas típicas desse construtivismo kantiano que estamos analisando.

Para concluir, gostaríamos de frisar rapidamente um dos problemas que a urgência de radicalização da democracia impõe sobre a ideia de razão pública de Rawls. Estamos nos referindo aqui, grosso modo, à crítica contra a restrição do liberalismo rawlsiano à ampliação da agenda política no interior da esfera pública.A ideia de que a razão pública pode ser discutida publicamente a qualquer momento estaria limitada pelos contornos estreitos do conceito do político no liberalismo. Uma limitação que a teoria da democracia de Habermas - para tomá-lo mais uma vez como critério comparativo na querela kantiana - com sua versão de um "republicanismo kantiano", procurou superar ao vincular novamente o que a ideia da razão pública em Rawls distinguiu como "cultura política pública", de um lado, e "cultura de fundo", de outro lado (Cf. HABERMAS, 1997; e MELO, 2008). Razões que podem contar como públicas ou não, bem como as fronteiras entre o justo e o bom, são estabelecidas pela própria dinâmica democrática de formação política da vontade, de modo que, como notou depois Seyla Benhabib, a separação entre política e cultura tem de ser sociologicamente interpretada como “institucionalmente instável". Os conflitos em torno de elementos essenciais da constituição colidem exatamente com os princípios a que se apegam os liberais, como nos casos de igualdade de gênero, integridade física, liberdade da pessoa, educação dos filhos e práticas de grupos e subculturas minoritárias. Tais manifestações questionam exatamente a separação entre cultura política pública e cultura de fundo, dificultando a interpretação e aplicação dessas práticas à luz dos princípios liberais (Cf. BENHABIB, 2002, p. 11).

Quando O’Neill diz que Kant é mais radical do que Rawls, a autora está sugerindo que o construtivismo kantiano é mais radical do ponto de vista da inclusão na deliberação pública e que também seria um forte candidato, seguindo a proposta de um "republicanismo kantiano", a 
escapar do paradoxo da justificação democrática. Pois a razão em Kant, afirma a autora, não pode estar "ancorada nas normas das comunidades (como supõem os comunitaristas) nem no consenso sobreposto dos cidadãos que partilham políticas eticamente diversas (como supõe Rawls): ela precisa ser, em princípio, acessível a todos, mesmo que estes convivam com diferentes normas e concepções de cidadania: ou seja, precisa ser acessível aos 'de fora' (outsiders)". (O’NEILL, 2003, p. 359). A estratégia kantiana de fundamentação não permitiria que se justificasse a moral e a justiça nem a aceitabilidade de estruturas de poder com base em valores éticos independentes da legitimação da razão. Diferentemente de Rawls, a autora sublinha que a concepção de razão prática em Kant não se limitaria ao uso público da razão vinculado ao exercício da cidadania nas democracias constitucionais. Pois não é a democracia constitucional (ou a cultura política que a condensa) que confere legitimidade à justificação da normatividade, mas antes são as próprias instituições políticas que precisam de justificação. Parece haver mais pluralismo pressuposto no "público irrestrito" de Kant do que o liberalismo político de Rawls soube reconhecer.

1 Professor de Teoria Política da UNIFESP e pesquisador do Núcleo Direito e Democracia do CEBRAP.

2 A primeira edição de $A$ Theory of Justice é de 1971. Utilizaremos aqui a edição revisada de 1999.

3 Essa é a tese presente em BAYNES, 1992. Tratamos do debate entre ambos os autores e alguns de seus pressupostos normativos kantianos - tal como a ideia de razão pública comum a ambos, o construtivismo kantiano de Rawls ou o republicanismo kantiano defendido por Habermas - em MELO, 2008, p. 113-141.

${ }^{4}$ Além do livro de Baynes citado na nota anterior, há também DARWALL, 1976; HÖFFE, 1984; DAVIDSON, 1985; e HABERMAS, 1997.

5 Cf. McINTYRE, 2001; SANDEL, 2005; TAYLOR, 2000; HONNETH, 2007.

6 Sobre o contratualismo rawlsiano, verVITA, 2000, p. 183-187.

7 O próprio Rawls acredita que em Kant já existe a tentativa de articular a justificação normativa a priori com pressupostos da construção, a saber, a concepção de pessoa e também uma concepção de sociedade. Cf. RAWLS, 2000a, p. 240. Para outros intérpretes, essa preocupação rawlsiana de partir da estrutura básica da sociedade explicitaria antes o aspecto hegeliano de sua teoria. Sobre este ponto, ver WELLMER, 1990, p. 293-329. 


\section{Referências bibliográficas}

BAYNES, K. (1992). The normative grounds of social criticism: Kant, Rawls, Habermas. New York: New York Press.

BENHABIB, S. (2002). The claims of culture. Princeton: Princeton University Press.

BITTNER, R. (2003). “Máximas”. In: Studia Kantiana, 5.

DARWALL, S. (1976). “A Defense of the Kantian Interpretation”. In: Ethics, 86.

DAVIDSON, A. (1985). “Is Rawls a Kantian?”. In: Pacific Philosophical Quarterly, 66.

HABERMAS, J. (1997). "Versöhnung durch öffentlichen Vernunftgebrauch". In: HABERMAS, J. Die Einbeziehung des Anderen. Frankfurt/M: Suhrkamp.

HÖFFE, O. (1984). “Ist Rawl's Theorie der Gerechtigkeit eine kantischer Theorie?”. In: Ratio, 26.

HONNETH, A. (2007). Sofrimento de indeterminação: Uma reatualização da filosofia do direito de Hegel. Tradução de Rúrion Melo. São Paulo: Singular/Esfera Pública.

KANT, I. (1995). Fundamentação da metafísica dos costumes. Tradução de Paulo Quintela. Lisboa: Edições 70.

(1977). "Beantwortung der Frage: Was ist Aufklärung”. In:

Kant, I. Schriften zur Anthropologie, Geschichtsphilosophie, Politik und Pädagigik. Werkausgabe Band XI. Frankfurt/M: Suhrkamp. (2002). Crítica da razão prática. Tradução de Valério Rohden. São Paulo: Martins Fontes.

McINTYRE, A. (2001). Depois da virtude. Tradução de Jussara Simões. São Paulo, EDUSC.

MELO, R. (2008). “O uso público da razão como procedimento: Um contraste entre Rawls e Habermas”. In: Dois Pontos, 5. 
O’NEILL, O. (1989). Constructions of reason. Cambridge University Press. (2003). "Constructivism in Rawls and Kant". In:

FREEMAN, S (org.). The Cambridge Companion to Rawls. Cambridge: Cambridge University Press.

RAWLS, J. (1999). A Theory of Justice. Oxford University Press. (2000a). Lectures on the history of moral philosophy. Harvard University Press, 2000. (2000b). O liberalismo político. Tradução de Dinah Azevedo. São Paulo: Ática. (2001a). Justice as fairness: A restatement. Harvard University Press. (2001b). "Kantian constructivism in moral theory". In: RAWLS, J. Collected Papers. Harvard University Press. (2007). "A idéia de razão pública revisitada". In: MELO, R./WERLE, D. L. (org.) Democracia deliberativa. São Paulo: Singular/Esfera Pública.

RORTY, R. (1988). “The priority of democracy to philosophy”. In: PETERSON, M./VAUGHAN, R. (org.) The Virginia Statute for Religious Freedom. Cambridge: CUP.

SANDEL, M. (2005). O liberalismo e os limites da justiça. Lisboa: Fundação Calouste Gulbenkian.

TAYLOR, C. (2000). “O debate liberal-comunitário”. In:TAYLOR, C. Argumentos filosóficos. Tradução de Adail Sobral. São Paulo, Loyola.

VITA, Á. (2000). A justiça igualitária e seus críticos. São Paulo: UNESP.

WELLMER,A. (1990). "Pratical philosophy and the theory of society: On the problem of the normative foundations os a critical social science". In: BENHABIB, S./DALLMAYR, F. (org.). The communicative ethics controversy. Cambridge: MIT Press.

WERLE, D. (2008). Justiça e democracia: Ensaios sobre John Rawls e Jürgen Habermas. São Paulo: Singular/Esfera Pública. 